\title{
Pensar coletivamente a regeneração dos centros urbanos antigos. Casos de Estudo: Portimão e Loulé - Portugal
}

Thinking collectively the regeneration of the historic inner city areas. Case Studies: Portimão and Loulé - Portugal

Pensar colectivamente la regeneración de los centros urbanos antiguos. Estudio de caso: Portimão y Loulé - Portugal

\author{
Lucinda Oliveira Caetano \\ Doutoranda, FA_UL, Portugal. \\ lucinda.caetano63@gmail.com \\ José Luís Crespo \\ Professor Doutor, FA_UL, Portugal. \\ jcrespo@fa.ulisboa.pt \\ Rodrigo Cury Paraízo \\ Professor Doutor, UFRJ, Brasil. \\ rparaizo@gmail.com
}





\section{INTRODUÇÃO}

Num contexto global onde a Nova agenda urbana da Conferência das Nações Unidas (HABITAT III, 2016) refere especificamente que "as cidades (...) para além de cumprirem a sua função social, devem ser participativas; promovendo o engajamento cívico; para gerar um sentimento de pertença e propriedade entre todos os seus habitantes", o uso de abordagens participativas na qualificação de territórios complexos tende a ser cada vez mais recorrente.

O presente trabalho integra uma investigação-ação de doutoramento que pretende desenvolver modelos de gestão participados para a regeneração urbana dos centros antigos algarvios, usando como casos de estudo os centros antigos de duas cidades: Loulé e Portimão. Para permitir uma correta interpretação do trabalho importa clarificar a definição de alguns vocábulos aqui utilizados, nomedamente: centro urbano antigo/ comunidade; regeneração urbana e participação pública.

\section{CENTRO URBANO ANTIGO/ COMUNIDADE}

Neste contexto evitou-se a utilização do termo "centro histórico" partindo do princípio de que a história encontra-se em construção permanente, ao passo que o "centro urbano antigo» reporta-se ao "tecido urbano edificado no tempo longo onde estão depositados os valores da urbes" (FERNANDES, 2014, p. 5).

Reforça-se a dicotomia referida por Françoise Choay (2004) entre cidade e urbano, ao avaliar que na cidade encontramos a junção entre urbes (suporte físico) e civitas («comunidade») enquanto o urbano apresenta "espaços construídos", cujo sistema operativo é válido em qualquer lugar, na cidade ou no campo.

Na definição da autora (p.70) "urbano" configura-se como um

sistema de referência física e mental, constituído por redes materiais e imateriais, assim como por objetos técnicos e cuja manipulação põe em jogo um repertório de imagens e informações, ressoa num circuito que se encerra sobre as relações que mantêm as nossas sociedades com o espaço, o tempo e os homens. (T.A.).

\section{REGENERAÇÃO URBANA}

Relativamente ao conceito de «Regeneração Urbana» considerando as diversas interpretações e consequentemente definições destas ações territoriais, julga-se conveniente sublinhar que adotamos a visão de Peter Roberts e Hugh Sykes (2000), no "Manual sobre regeneração urbana" onde definem regeneração (p.17) como uma "visão abrangente e integrada e simultaneamente como uma ação que objetiva uma melhoria duradoura nas condições econômica, física, social e ambiental de uma área que passou por alterações". (T.A.) 
Em termos de definição utilizaremos o definido no quadro estratégico português atual Estratégia Cidades Sustentáveis 2020 (aprovada com a Resolução do Conselho de Ministros n.o 61/2015, de 16 de julho) - onde consta a definição de «Regeneração urbana» como a

\begin{abstract}
Valorização integrada do conjunto do suporte físico urbano (parque edificado, infraestruturas, condições ambientais e paisagísticas) e promoção do desenvolvimento funcional, cultural, social e económico das áreas urbanas, procurando alcançar soluções de compromisso estratégico e operacional entre os diversos agentes territoriais (públicos, privados e associativos).
\end{abstract}

\title{
PARTICIPAÇÃO PÚBLICA
}

No que concerne à literatura sobre "participação pública» existem diferentes tipos e definições sobre participação - ativa, semi-ativa e passiva.

De acordo com a Organização para a Cooperação e Desenvolvimento Económico (OCDE) a participação é considerada ativa quando os

\begin{abstract}
cidadãos se envolvem ativamente na tomada de decisão e na formulação de políticas. Participação ativa significa que os próprios cidadãos assumem um papel na formulação de políticas como, por exemplo, quando propõem opções políticas. Ao mesmo tempo, a responsabilidade pela formulação de políticas e a decisão final, recaem sobre o governo. Envolver os cidadãos na formulação de políticas é uma relação bidirecional avançada entre o governo e os cidadãos, baseada no princípio de parceria (OCDE, 2002, p. 22).
\end{abstract}

No entanto, de acordo com outros autores, a verdadeira participação ativa implica o empoderamento da sociedade civil, ou seja,

supõe uma interação dinâmica entre todos os participantes externos e internos, ou técnicos e comunidade, em todas as fases do processo, desde as primeiras fases de definição das estratégias até a tomada de decisões. Neste tipo de participação, promove-se a comunicação e o diálogo entre os envolvidos, sob a forma de conversas, reuniões de grupos abertos ou pequenos, bem como, sessões coletivas de trabalho, facilitando um resultado mais conforme com os objetivos locais e com o empoderamento das comunidades (VASCONCELOS, 2007, apud RAPOSO et al., 2017, p.11).

Neste âmbito o que a OCDE denomina "participação ativa" julga-se mais adequado defini-la como "participação semi-ativa", ou seja, reporta-se aos processos de participação onde a opinião publica poderá vir a ser adotada, se for considerado pertinente pela Administração Pública, aquando da ponderação. Por outro lado, será passiva se estiver 
associada a ações como a informação e consulta às populações, e geralmente corresponde à fase final dos processos, após as decisões determinantes terem sido tomadas por técnicos e políticos. Os casos em questão são audiências públicas onde os presentes podem ser ouvidos, podem obter informações e dúvidas claras sobre o processo em discussão, mas não tomam parte em decisões. (T.A.) (RAPOSO et al., 2017, pp 10-11).

\section{OBJETIVOS E ABORDAGEM}

O presente trabalho tem como objetivo principal a disseminação dos resultados de dois workshops realizados com atores sociais vinculados aos centros urbanos antigos, de duas cidades portuguesas: Portimão e Loulé, cujos objetivos específicos eram fomentar a cocriação de políticas de regeneração urbana dos centros antigos, através de um trabalho de reflexão coletiva, dirigida com base em metodologias específicas.

O conteúdo teórico fornecido para o trabalho coletivo baseou-se na ótica de que o sistema urbano é composto por vários subsistemas - político, económico, territorial, social e cultural logo, a "regeneração urbana" passará, necessariamente, pela promoção do equilíbrio e articulação desses vários subsistemas, bem como, das relações entre eles, ou seja, da articulação das políticas urbanas, da sua materialização e dos atores do processo de planeamento.

Nesse âmbito, antecendo a reflexão coletiva foram discutidos conceitos como a dicotomia entre cidade e urbano (CHOAY, 2004), os "não-lugares", na definição de Augé (2012) e definidos coletivamente os elementos de identidade urbana/ memória urbana da zona antiga das cidades, no decurso temporal - presente, passado e futuro -, avaliando: o que permanece - Narrativas da Cidade -; e o que desejam "ser"/ "ter" - Projeções futuras.

A abordagem utilizada na discussão entre os vários atores sociais, baseou-se no diagnóstico dos problemas, na análise dos recursos em presença e na apresentação de propostas de ação concretas para a regeneração/ revitalizaçao urbana dos centros antigos em estudo, cuja discussão era induzida/ moderada por um facilitador por mesa. Evidentemente por se tratarem de núcleos urbanos de reduzida dimensão, praticamente todos os participantes se conheciam (tendo estes sido convidados pela equipa organizadora ou levados por amigos que haviam sido convidados), no entanto os workshops foram iniciados com uma breve apresentação de todos, do contexto e dos objetivos que se pretendiam atingir com o trabalho. Após a apresentação geral os participantes foram convidados a sentarem-se na mesa que lhes estava pré-definida com base em critérios da investigação, mais à frente explicitados.

\section{CONTEXTO TERRITORIAL/ POLÍTICO/ SOCIAL E CULTURAL}

Os Casos de Estudo - Portimão e Loulé - integram a região algarvia, banhada a sul e poente pelo Oceano Atlântico, separada de Espanha pelo Rio Guadiana e do Alentejo pelas ribeiras de 

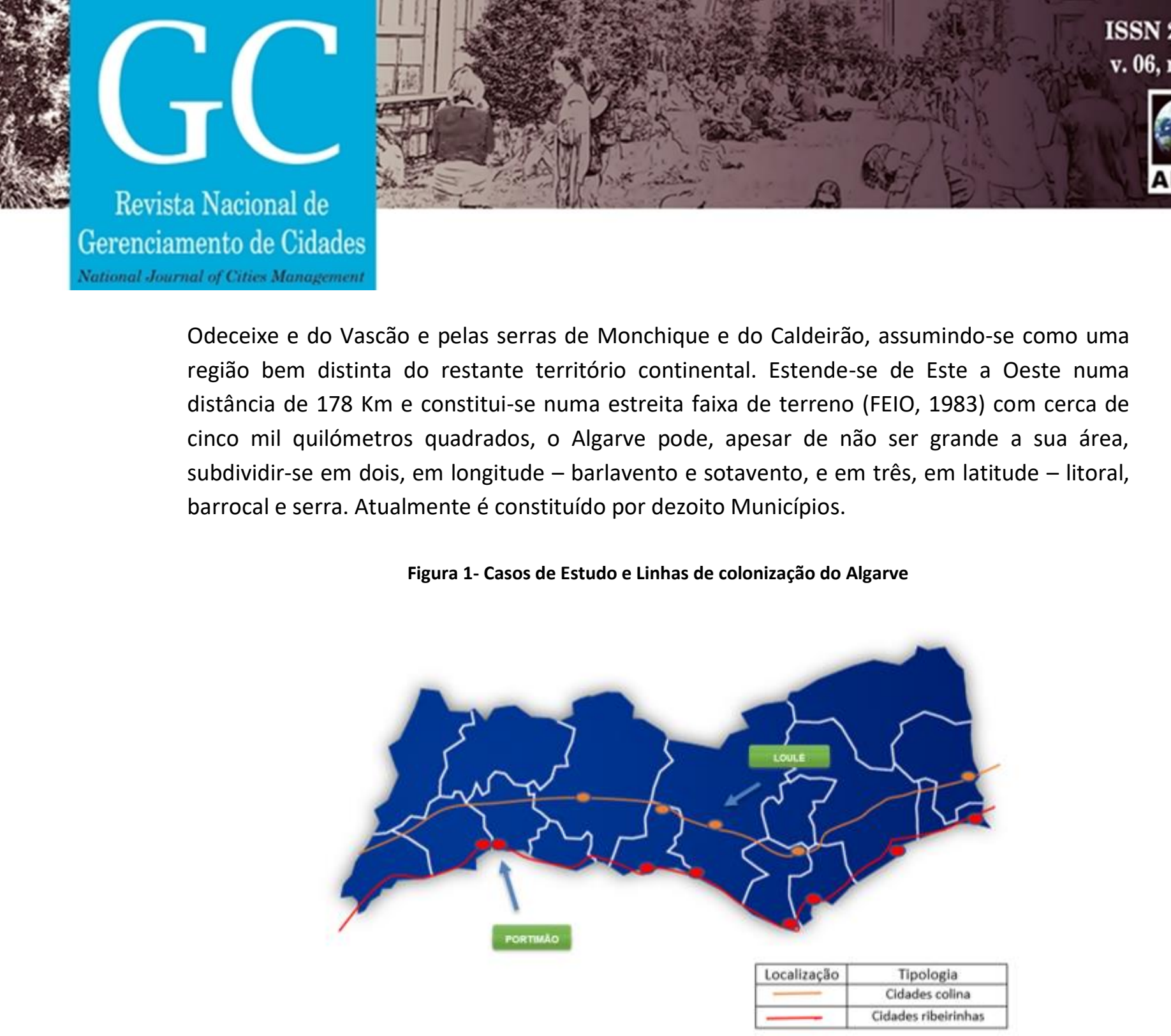

Fonte: CAETANO et al., no prelo

Da história da formação territorial do Algarve há dois factos que importam reter: a aptidão da costa para a indústria conserveira (tanto durante a ocupação romana - século II ao VI a.C. verdadeiro Complexo Industrial Romano de Salga e Conserva de Peixe, conforme comprovam as escavações arqueológicas ao longo da costa, incluindo Portimão - Portus Magnus - quanto do advento da indústria conserveira no início na primeira guerra mundial de 1912-1918) (RODRIGUES, 2011); e a relação histórica de complementaridade entre as urbes do litoral (cidades ribeirinhas) e do interior (cidades Colinas) - Portimão/ Silves, Alvor/ Mexilhoeira Grande, Quarteira/ Loulé, entre outras.

A partir da década de 60 do século XX, as cidades ribeirinhas algarvias, entre elas Portimão, sofreu a pressão turística, devido à proximidade com a linha de costa - Praia da Rocha e Alvor - o aumento de soberania do poder local (após a revolução dos Cravos, em 1974) sobre as políticas urbanas e a ausência de Planos urbanísticos reguladores legalmente aprovados e publicados. Este facto trouxe graves problemas territoriais, dos quais a excessiva densidade de construção tanto a nível do solo, quanto em altura, nas zonas costeiras aliada à construção 


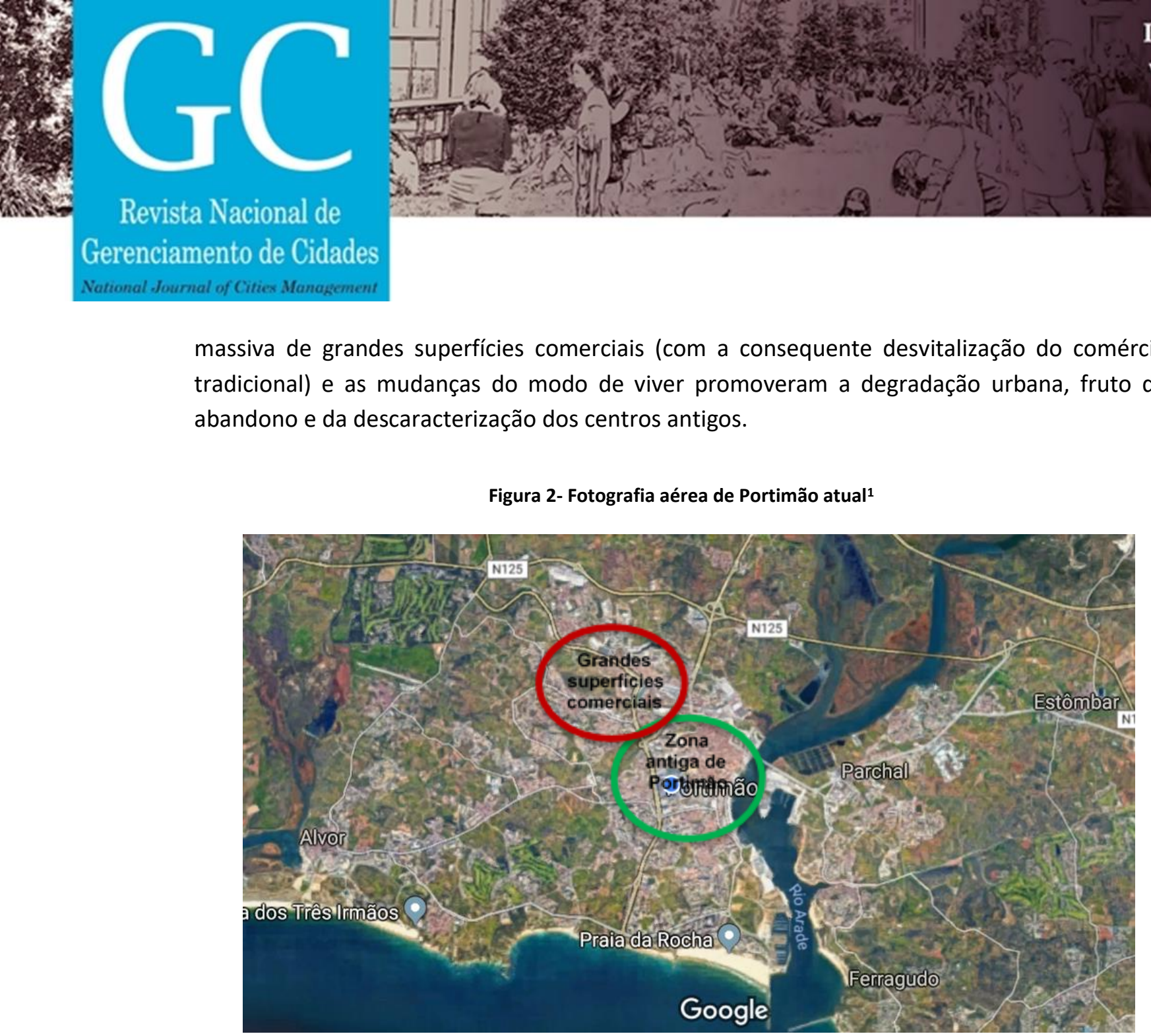

ISSN 2318-8472

v. 06, n. 40,2018

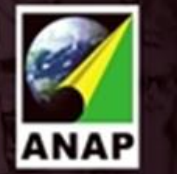

\section{Gerenciamento de Cidades}

massiva de grandes superfícies comerciais (com a consequente desvitalização do comércio tradicional) e as mudanças do modo de viver promoveram a degradação urbana, fruto do abandono e da descaracterização dos centros antigos.

Figura 2- Fotografia aérea de Portimão atual ${ }^{1}$

Como se pode observar nas Figuras 2 e 3, tanto em Portimão quanto em Loulé, a ocupação territorial segue o padrão da urbanização descontínua e fragmentada, num amálgama de formas urbanas e vivências dispersas, sendo um dos problemas mais complexos e atuais das cidades contemporâneas europeias.

\footnotetext{
${ }^{1}$ In «https://www.google.pt/maps/@37.1398938,-8.5359062,7685m/data=!3m1!1e3», consultado em março 2018.
} 


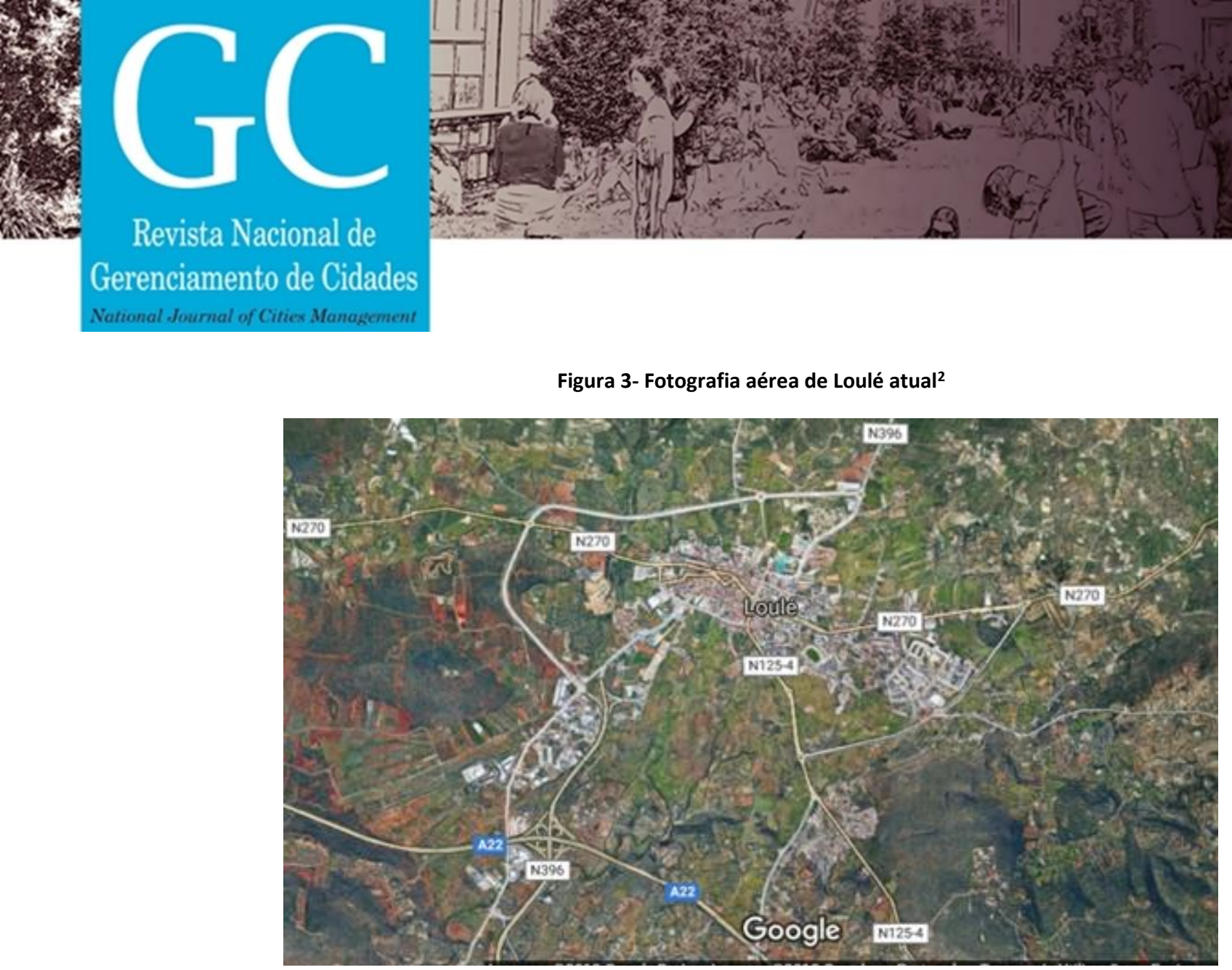

No entanto, a cidade de Loulé, sede do Município, usufrui da confortável situação financeira da Câmara Municipal devido, sobretudo, aos empreendimentos turísticos de luxo existentes no litoral, cuja especulação imobiliária incidiu mais fortemente em Quarteira, permitindo a preservação do centro urbano antigo de Loulé, ainda que sentindo os reflexos da pouca atratividade para reter novos moradores e visitantes.

As políticas urbanas para Loulé, em especial a partir de 2003, tinham como intenção a preservação do aglomerado urbano antigo, a contenção da construção em altura e a não permissão de implantação de grandes superfícies comerciais nas proximidades. Por outro lado, servindo-se de uma política cultural potenciadora do centro antigo e da "marca" Loulé que projetou a cidade, colocando-a no circuito turístico cultural internacional. Simultaneamente iniciou uma política de reabilitação/ revitalização dos espaços públicos e privados da Câmara, inseridos no centro antigo a par com escavações arqueológicas e de potenciação de projetos criativos, reforçando aspetos identitários, alguns deles advindos de associações locais, como a recuperação de profissões antigas e a captação de jovens aprendizes.

Para contextualizar os casos de estudo considerou-se importante apresentar alguns parâmetros territoriais e humanos comparativos, conforme a tabela 1.

\footnotetext{
2 In «https://www.google.pt/maps/@37.1345025,-8.0181797,5436m/data=!3m1!1e3», consultado em março de 2018.
} 


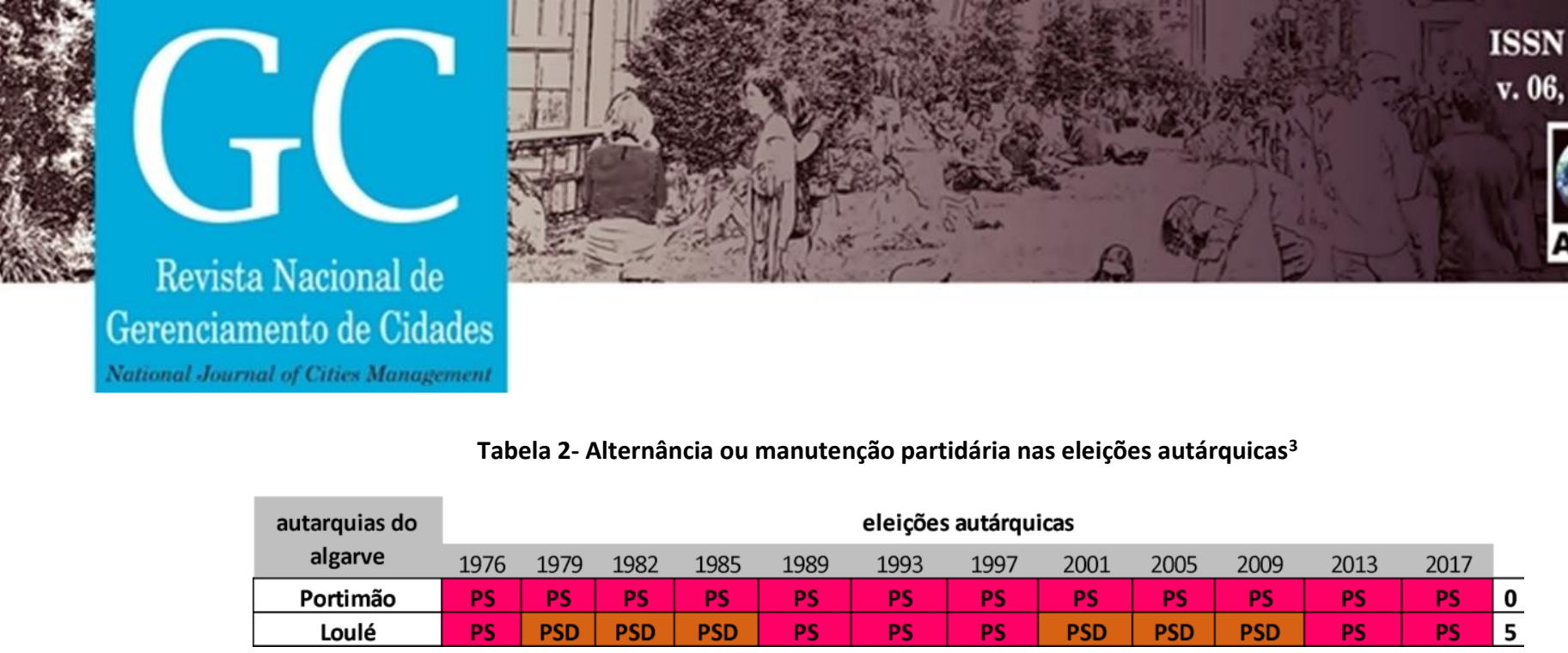

Fonte: $\mathrm{CNE}^{4}$ (Comissão Nacional de Eleições)

\section{METODOLOGIAS PARA AS AÇÕES DE INVESTIGAÇÃO E PARA A AÇÃO}

A seleção dos parceiros para a realização das ações com as comunidades, em cada caso de estudo - Portimão e Loulé - baseou-se na análise da relação entre os vários atores sociais, com base no conhecimento/ observação direta; avaliação da incidência e tipologia de participação pública nos vários fóruns democráticos, tais como, reuniões da Câmara Municipal públicas, sessões das Assembleias Municipais; participação pública no âmbito dos instrumentos de gestão territorial, e no caso de Loulé no Orçamento Participativo; corroborada em entrevistas semi-estruturadas a atores- chave das comunidades.

Desse modo, as acções no território realizaram-se com parcerias entre o Centro de Investigação, da Faculdade de Arquitectura, da Universidade de Lisboa com organizações "institucionais" e/ ou da sociedade civil, de acordo com as especificidades locais, com o intuito de criar o ambiente mais favorável possível, propiciador de uma participação pública ativa.

Nesses termos, em Portimão, celebrou-se um protocolo com duas Associações da sociedade civil - Teia D'Impulsos (com cariz cultural e de cidadania) e Contramaré (com cariz cultural, em especial na área da música) - e, em Loulé, com a Câmara Municipal de Loulé, a Escola Secundária de Loulé e duas Associações da sociedade civil - Casa da Cultura de Loulé (de cariz cultural) e com a delegação de Loulé da ACRAL (Associação do Comércio e Serviços da Região do Algarve).

Para guiar-nos na metodologia a aplicar nos Workshops recorreu-se a uma pré-abordagem do "pensar e sentir" da comunidade, através de inquéritos exploratórios (que iriam alimentar o foco dos Workshops em cada caso de estudo), distribuídos por determinados grupos sociais, utilizadores do espaço em estudo e participantes em ações culturais e cívicas.

\footnotetext{
3 Normalmente entre o Partido Socialista (PS) e o Partido Social Democrático (PSD), estando o PS identificado como centro esquerda e o PSD como centro direita.

${ }^{4}$ In http://www.cne.pt/content/homepage. Consultado em 22.maio.2018.
} 
O inquérito foi estruturado em três partes distintas: Caracterização dos Inquiridos, Identificação com Espaço e Memória/ Identidade Urbana, utilizando um conjunto de questões fechadas deixando algumas perguntas abertas, para permitir a partilha de ideias.

Em termos comparativos, conforme a Tabela 3, verificamos que os inquiridos de Loulé apesar de se dividirem equitativamente entre naturais e moradores (tal como em Portimão) e de não estarem tão homegeneizados em termos de formação académica de nível superior como em Portimão, conhecem melhor a história, gostam e identificam-se mais com a sua cidade.

O formato dos Workshops, cujos participantes foram selecionados por convite, foi idealizado para ser dividido em mesas de trabalho com cinco elementos cada, das quais todas as mesas (exceto uma) seriam selecionadas por "interesse" ou "papel social", exceto um grupo de controlo (multidisciplinar) composto por um elemento de cada grupo. Esta divisão dos participantes relacionou-se com a intenção de deixar todos "entre pares", sendo cada grupo mediado por um facilitador "neutro" que não participando da discussão, tinha como função garantir que todos teriam direito a falar e que não perderiam o foco durante a discussão.

Tabela 3 - Resultados comparativos dos Inquéritos Exploratórios

\begin{tabular}{|c|c|c|}
\hline \multicolumn{3}{|c|}{ Resultados comparativos - Inquéritos - Identidade Urbana } \\
\hline Questões & Portimão & Loulé \\
\hline Total de inquiridos & 65 & 73 \\
\hline Recolha dos Inquéritos & $\begin{array}{l}\text { Tertúlia realizada pela Teia } \\
\text { D'Impulsos em } 5 \text { DEZ } 2017 \text { (25) } \\
\text { Feira de Natal promovida pela } \\
\text { Contramaré em } 8 \text { DEZ } 2017 \text { (14) } \\
\text { Workshop de } 27 \text { JAN } 2018 \text { (16) }\end{array}$ & $\begin{array}{l}\text { Inquéritos enviados por e-mail para } \\
\text { os funcionários da Câmara } \\
\text { Municipal de Loulé (36) } \\
\text { Preenchimento on-line criado pela } \\
\text { Casa da Cultura (15) } \\
\text { Preenchimento em papel pelos } \\
\text { sócios da ACRAL-Loulé (22) }\end{array}$ \\
\hline Faixa etária predominante & $20-80$ anos (equilibrado) & $\begin{array}{l}52 \% \text { entre } 40-60 \text { anos/ } \\
33 \% \text { entre } 20-40 \text { anos }\end{array}$ \\
\hline Escolaridade predominante & $\begin{array}{l}\text { 45\% Licenciatura/ } \\
20 \% \text { Mestrado }\end{array}$ & $\begin{array}{l}44 \% \text { Licenciatura/ } \\
29 \% \text { Secundário }\end{array}$ \\
\hline Ligação à cidade & $57 \%$ Vivem/ 34\% Nascidos & $\begin{array}{l}\text { 43\% Vivem/ 36\% Nascidos/ } \\
22 \% \text { Trabalham }\end{array}$ \\
\hline Conhecimento da cidade & $\begin{array}{l}\text { 62\% Razoável/23\% Pouco/ } \\
9 \% \text { Bem }\end{array}$ & $\begin{array}{l}\text { 51\% Razoável/ 22\% Pouco/ } \\
\text { 22\% Bem }\end{array}$ \\
\hline Características urbanas & $\begin{array}{l}\text { Com valor/Interessante/ } \\
\text { Sem atração/Bonito-feio }\end{array}$ & $\begin{array}{l}\text { Interessante/Com valor/ Bonito/ } \\
\text { Atrativo }\end{array}$ \\
\hline Gostar do centro antigo & $65 \% \operatorname{sim} / 15 \%$ não & $84 \% \operatorname{sim} / 1 \%$ não \\
\hline Identificação com o centro antigo & $45 \%$ não/ 37\% sim & $62 \% \operatorname{sim} / 23 \%$ não \\
\hline $\begin{array}{l}\text { Deviam fazer-se mudanças no } \\
\text { centro antigo? }\end{array}$ & $75 \% \operatorname{sim} / 3 \%$ não & $88 \% \operatorname{sim} / 5,5 \%$ não \\
\hline
\end{tabular}

Para fomentar a discussão e a reflexão foram usadas ferramentas de Service Design para organizar Pessoas, Processos, Métodos e Parceiros de forma a se obter a melhor e mais satisfatória experiência dos usuários e clientes, entendendo e atendendo às suas necessidades e desejos no desenho de soluções, tais como - the group sketching, the character profiles, the customer journey map e the affinity diagram - delineando-se coletivamente uma estrutura 
não vieram todos os representantes das Associações convidadas, por isso agruparam-se numa mesma mesa os moradores e as associações.

Cada mesa de trabalho em cada workshop concluiu a sessão de trabalho com a definição de dois problemas, dois recursos e duas soluções/ propostas de ação, contextualizados aos centros antigos em estudo, que não serão aqui discutidos em pormenor porque totalizam doze em Portimão e dezasseis em Loulé, sendo alguns repetidos. No entanto, para efeitos de sistematização comparativa compilámos todas as conclusões finais, agrupando-as em linhas temáticas e verificando as incidências por mesa em cada caso de estudo.

Os resultados obtidos nos dois workshops foram apresentados às respetivas populações em tertúlias posteriores, as ideias foram retomadas nos workshops seguintes que tratavam da discussão de canais de participação, onde foram selecionados os melhores canais para a comunidade apresentar as propostas ao poder local.

\section{Gráfico 1 - Temas e incidências em Portimão}

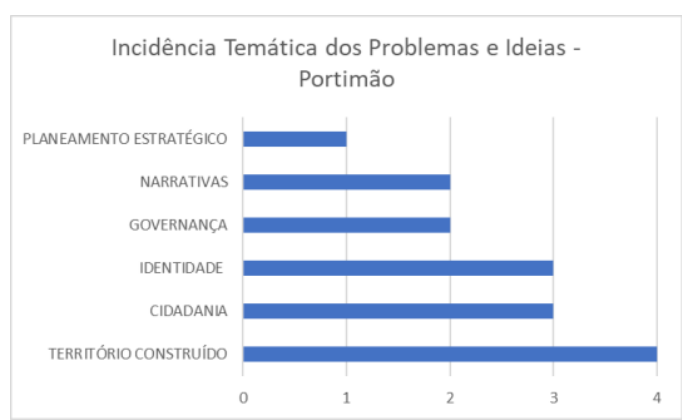

Com se verifica no Gráfico 1, no caso de Portimão, para cada problema foi procurada uma solução, sendo os três temas mais recorrentes das seis mesas de trabalho, o território construído, a identidade e a cidadania. Saliente-se que não se observou discrepância entre o conteúdo da discussão e dos resultados entre o grupo de controlo e as outras mesas.

Gráficos 2 e 3 - Temas dos problemas e ideias e incidências em Loulé

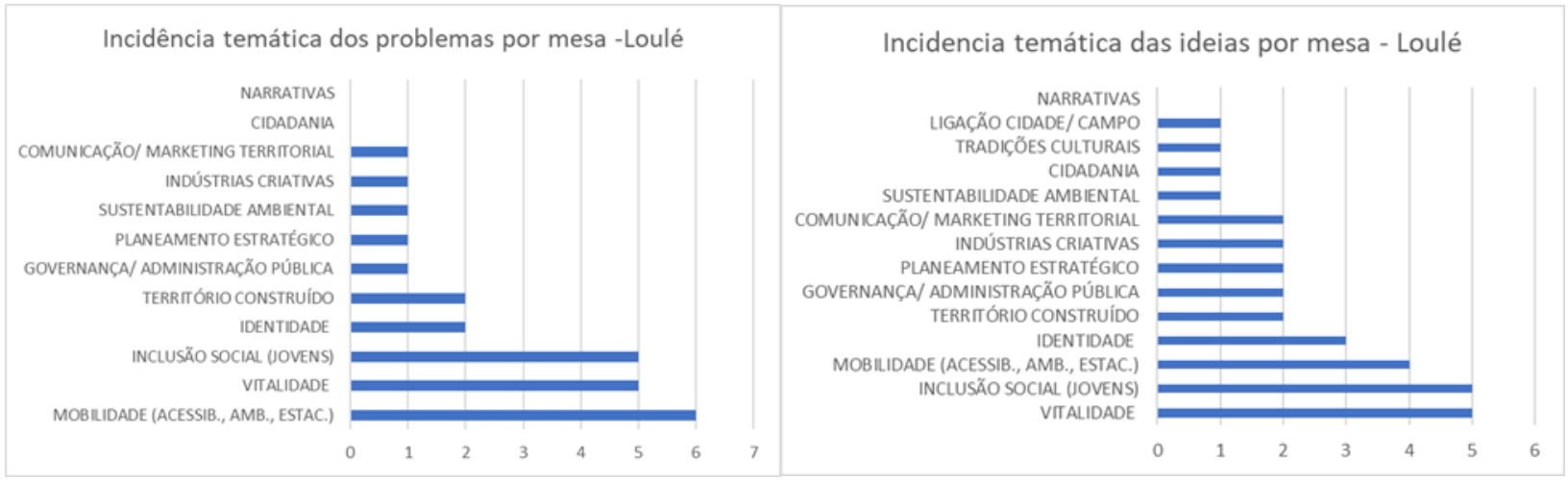





\section{AGRADECIMENTOS}

Os autores gostariam de agradecer ao CIAUD, à FA da ULisboa e ao PROURB da UFRJ o apoio na investigação; e à FCT o financiamento dos trabalhos conducentes ao Doutoramento. Agradecem também às Instituições parceiras no estudo em curso, nomeadamente Associação Teia D'Impulsos (Portimão), Associação Contramaré (Portimão), Câmara Municipal de Loulé, Escola Secundária de Loulé, Casa da Cultura de Loulé e Delegação de Loulé da ACRAL. Cabe também uma nota de agradecimento especial ao Professor Doutor João Cabral (FA ULisboa) pelo apoio incondicional ao trabalho; ao trabalho voluntário dos facilitadores com uma nota especial para Ana Rita Queirós (GEU) pelo seu empenho na concretização destas ações.

\section{REFERÊNCIAS BIBLIOGRÁFICAS}

AUGÉ, Marc. Não-Lugares, Introdução a uma antropologia da sobremodernidade. Lisboa: Letra Livre, 2012.

BRANDÃO, Pedro. O Sentido da Cidade, Ensaios sobre o mito da imagem como arquitectura. Lisboa: Livros Horizonte, 2011.

CAETANO, Lucinda Oliveira et al. Narrativas Urbanas: Centros Antigos e Comunidades. Os Casos de Portimão e Loulé, Algarve, Portugal. Rio de Janeiro, No prelo.

CHOAY, Françoise. El reino de lo urbano y la muerte de la ciudad. In Lo Urbano en 20 autores contemporáneos. Barcelona: Editções UPC, 2004.

FEIO, Mariano. O Baixo Alenteio e o Algarve. Évora, 1983.

FERNANDES, Sérgio. Gênese e Forma dos Traçados das Cidades Portuguesas. Morfologia, Tipologia e Sedimentação. Tese Doutoral. Lisboa: Faculdade de Arquitetura. Universidade de Lisboa, 2014.

OCDE. O Cidadão como Parceiro, Manual da OCDE sobre Informação, Consulta e Participação na formulação de políticas públicas. MP SEGES, Brasília, 2002. 124 p. CDU 332.145+316.43

RAPOSO, Isabel et al. Participatory approaches in the qualification of semi-urbanised peri-urban areas: The case of the Odivelas Vertente Sul Area. In Mendes, M. et al. (Eds.) Architecture and he Social Sciences. Inter-and Multidisciplinary Approaches between Society and Space. Springer, 2017. pp. 151-176.

ROBERTS, Peter; SYKES, Hugh. Urban Regeneration: A Handbook. SAGE Publications, 2000.

RODRIGUES, Joaquim Manuel Vieira. A indústria de conservas de peixe no Algarve (1865-1945), 1997; Ferreira, Álvaro Joaquim Fernandes - As conservas enlatadas na alimentação das tropas em campanha, 1949; Ramirez, Memórias de cinco gerações, Edição da empresa, 2011.

URBINATI, Nadia. O Que Torna a Representação Democrática? In Atas do Encontro Anual da American Political Science Association (Apsa), Washington (EUA), setembro de 2005. Tradução de Mauro Soares. São Paulo: Lua Nova, 2006. pp. 191-228. 